\title{
Pesquisa e formação profissional continuada: (em) caminhos da educação inclusiva
}

\author{
Carla Helena Fernandes \\ Programa de Mestrado em Educação da Universidade do Vale do Sapucaí, Pouso Alegre, MG - Brasil \\ carlahelenafernandes@yahoo.com.br
}

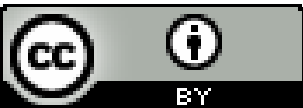

EDUCAÇÃO: Teoria e Prática, Rio Claro, SP, Brasil - elSSN: 1981-8106

Está licenciada sob Licença Creative Common

\section{Resumo}

O texto apresenta discussão acerca da relação entre pesquisa, formação continuada do professor e a reconstrução dos saberes docentes (TARDIF, 2007); tem como referência investigação desenvolvida em uma escola pública municipal, com professores dos anos finais (sexto ao nono) do Ensino Fundamental. O objetivo da pesquisa era investigar processos de formação desenvolvidos na escola, e empregou como instrumentos entrevistas semiestruturadas, realizadas com esses professores. Foram, também, analisados textos de sua autoria sobre a prática pedagógica, entre eles os Relatórios de Pesquisa elaborados pelos professores participantes de projeto de pesquisa desenvolvido na escola, que visava à solução das dificuldades desses profissionais junto a alunos que solicitavam outras formas de ensinar e de aprender. Os resultados da pesquisa afirmaram que, tendo como foco a contemporaneidade e a realidade dos alunos e da escola, a investigação sobre a própria prática e a escrita desse processo promovem interlocuções e reflexões necessárias à reconstrução dos saberes dos docentes. Especificamente, em relação aos alunos que mobilizavam as buscas dos professores, esses novos saber e fazer do professor podem contribuir na sua aprendizagem por meio da construção da educação escolar realmente inclusiva.

Palavras-chave: Formação Profissional Continuada. Pesquisa. Saberes Docentes. Educação Inclusiva.

\section{Research and continuing education teacher: (in) ways of inclusive education}

\begin{abstract}
The text presents discussion about the relationship between research, continuing education teacher and reconstruction of teacher knowledge (TARDIF , 2007) and is referenced research conducted in a public school, with teachers from the final years ( sixth to ninth ) Elementary School. The objective of the research was to investigate formation processes developed in school and employed as instruments semi-structured interviews with these teachers. Also analyzed were of his texts on teaching practice, including the Research Reports prepared by
\end{abstract}


teachers participating in the research project developed at the school, which aimed at solving the difficulties of these professionals with students requesting other forms of teaching and learning. The survey results indicated that, with a focus on contemporary reality and the students and the school, the research on their own practice and the writing process that promote dialogues and reflections necessary reconstruction of knowledge of teachers. Specifically in relation to students who mobilized searches teachers, this new knowledge and making the teacher can contribute in their learning through the construction of school education really inclusive.

Keywords: Continuing Education Teacher. Research. Teaching Knowledge. Inclusive Education.

\section{Investigación y formación profesional continuada: (en) caminos de la educación inclusiva}

\section{Resumen}

El texto presenta la discusión acerca de la relación entre investigación, formación continua del profesor y la reconstrucción de los saberes docentes (TARDIF, 2007). Tiene como referencia la investigación desarrollada en una escuela pública municipal, con profesores de los años finales (sexto a noveno)* de la Enseñanza Fundamental. El objetivo del estudio era investigar procesos de formación desarrollados en la escuela y se emplearon entrevistas semiestructuradas como instrumentos de investigación, realizadas con esos profesores. También se analizaron textos de su autoría sobre la práctica pedagógica, entre ellos los Informes de Investigación elaborados por los profesores participantes del proyecto de investigación desarrollado en la escuela, que tenía como objetivo la solución de las dificultades de esos profesionales con los alumnos que solicitaban otras formas de enseñar y de aprender. Los resultados de la investigación afirmaron que, teniendo como foco la contemporaneidad y la realidad de los alumnos y de la escuela, la investigación sobre la propia práctica y la escritura de ese proceso promueven interlocuciones y reflexiones necesarias para la reconstrucción de los saberes de los docentes. Específicamente, con relación a los alumnos que motivaban las búsquedas de los profesores, esos nuevos saber y hacer del profesor pueden contribuir en su aprendizaje por medio de la construcción de la educación escolar realmente inclusiva.

Palabras clave: Formación Profesional Continua. Investigación. Saberes Docentes. Educación Inclusiva.

* En el currículo brasileño, estos cursos corresponden a la Enseñanza Fundamental II, que atiende a alumnos entre los 12 y 15 años, considerando el ingreso del alumno a la educación básica a los 6 años.

\section{Introdução}

A contemporaneidade tem colocado grandes desafios aos profissionais da educação, dentre eles a construção de escolas que realmente atendam à diversidade que as 
constitui, o que tem exigido reflexões e mudanças para o atendimento de todas as crianças e jovens, também aqueles que apresentam necessidades educacionais especiais (UNESCO, 1998b).

Tal construção solicita pensarmos sobre os macro e microespaços educacionais e as ações político-pedagógicas necessárias aos diferentes contextos escolares. Nesses espaços, é fundamental que se pense a construção de práticas pedagógicas inclusivas, voltadas a ensinar alunos com atuação e desenvolvimento diversos, sendo os professores importantes agentes dessa construção. Para além do discurso do despreparo, solicita-se, nesse sentido, a formação profissional continuada, alicerçada, sobretudo, na ressignificação dos saberes e do fazer docente (TARDIF, 2007), tendo em vista o próprio exercício profissional e o cotidiano escolar.

Trata-se de compreender a formação no espaço da atuação profissional, na complexa construção escolar e, em convergência com essa perspectiva de formação, afirmamos que as reflexões propiciadas por pesquisas desenvolvidas pelo professor, e com o professor, podem possibilitar as reafirmações e/ou as (trans)formações necessárias à contemporaneidade, levando em conta, também, a construção da inclusão escolar, podendo caracterizar-se como processo realmente formativo para os sujeitos envolvidos.

Visando refletir sobre essa temática - a relação entre pesquisa, formação profissional e a reconstrução dos saberes dos professores - este artigo foi organizado em duas partes: na primeira, apresenta-se discussão sobre esses temas; na segunda, apresentase pesquisa de campo desenvolvida em uma escola pública municipal do interior do Estado de São Paulo, ${ }^{1}$ que visou, tendo como encaminhamento a abordagem qualitativa e a pesquisa colaborativa (FIORENTINI, 2004), investigar a formação continuada de professores na escola, a partir das necessidades e complexidade do exercício docente e do cotidiano escolar.

Uma vez que esses professores participavam, à época, de pesquisa desenvolvida coletivamente na escola em parceria com um grupo de pesquisadores-professores de uma universidade local, tal fato foi considerado fundamental em nossas reflexões sobre a formação profissional continuada, na perspectiva de formação como construção-

${ }^{1}$ Tal pesquisa resultou na tese de doutoramento da autora deste artigo, intitulada Dizeres de professores da/na formação continuada: possibilidades de autoria, defendida junto ao Programa de PósGraduação da Faculdade de Educação da UNICAMP, em 2009. 
desconstrução contínua dos saberes docentes a partir da escola e da sala de aula, o que, no caso apresentado, demandava práticas pedagógicas voltadas a alunos que solicitam outras e novas formas de ensinar e outro olhar acerca de sua aprendizagem e seu desenvolvimento.

\section{Formação profissional continuada, pesquisa e a reconstrução das práticas pedagógicas}

A busca por uma educação que atenda a todos os alunos em suas particularidades, potencialidades e necessidades exige que se reflita sobre práticas pedagógicas que atendam a essa diversidade; porém é imprescindível contextualizar tal discussão de modo mais amplo, considerando questões relativas à escola e à sala de aula, à observação das dinâmicas e às relações estabelecidas nesses espaços. E, especificamente no que diz respeito aos processos de ensinar e aprender, um dos aspectos que se deve ressaltar, a nosso ver, é a relação entre a construção das práticas pedagógicas e a formação do professor, compreendida como contínua e processual, a qual, partindo dos saberes da formação inicial, estabelece diálogo com os saberes da experiência, do cotidiano e do exercício docente (TARDIF, 2007) Trata-se de uma perspectiva de formação profissional que considera a realidade concreta da escola e dos alunos, em substituição a concepções e práticas de formação baseadas em verdades absolutas e imutáveis, e que têm por foco um aluno idealizado.

Sob nossa perspectiva, as pesquisas desenvolvidas pelos e com os professores se mostram adequadas como práticas de reflexão e formação. Reafirmamos a importância da figura do professor-pesquisador, a que se dedicou Stenhouse (1975), um dos primeiros que se ocupou da pesquisa na relação com a docência em todos os níveis de ensino, tanto nas universidades quanto nas escolas. Na construção histórica dessa abordagem, Elliott (1998) acrescentou aos estudos iniciais, desenvolvidos por Stenhouse, outras investigações acerca de modalidades de pesquisa que relacionavam, na escola, as ações dos pesquisadores com as dos professores. Na década de 90, Zeichner (1998a; 1998b) reiterou a ideia de pesquisa na escola como ação e reflexão crítica do professor sobre o trabalho docente, indicando o vínculo da docência com o contexto escolar e social. A reflexão, para o autor, deveria ter por foco o posicionamento crítico capaz de gerar mudanças. 
No Brasil, diferentes grupos de pesquisadores têm se dedicado a essa temática. Ressaltamos, aqui, a produção voltada ao estudo da formação profissional centrada no contexto do trabalho e com a participação de professores e pesquisadores da escola e da universidade, entre estes: Geraldi, Fiorentini e Pereira (1998); Prado e Soligo (2005); Varani, Ferreira e Prado (2007); Prado e Cunha (2007) e Vicentini et al (2008).

A necessidade de atender à diversidade de sujeitos e contextos que constituem a escola brasileira, fruto dos movimentos de democratização e universalização da educação básica, tornou contemporânea a temática do professor que pesquisa sua própria prática no contexto da escola, sendo que essa construção solicita a ressignificação de saberes e práticas e o afastamento de certezas pedagógicas calcadas em verdades objetivas.

Japiassu (1983) afirma que toda ação docente deve pautar-se por incertezas potencializadoras de buscas e reflexões, para as quais contribui um posicionamento investigativo do professor. A incerteza vivida não é inadequada à prática profissional; é, ao contrário, condição para o desenvolvimento da crítica, da criatividade e da autonomia em relação a esquemas pré-concebidos e dogmáticos. Ainda segundo Japiassu, as certezas pedagógicas precisam ser desconstruídas, principalmente, acrescentamos, as certezas acerca dos saberes da formação inicial e dos supostos alunos idealizados.

Nesse mesmo pensar, Tardif (2007) comenta a contínua ressignificação dos saberes docentes. Para ele, a prática dos professores integra diferentes saberes com os quais se estabelecem diferentes relações, sendo, assim, possível definir o saber docente como um "saber plural, formado pelo amálgama, mais ou menos coerente, de saberes oriundos da formação profissional e de saberes disciplinares, curriculares e experienciais" (TARDIF, 2007, p. 36). Se os três primeiros - saberes da formação profissional, disciplinares e curriculares são produzidos pelas ciências da educação, transformados em programas e transmitidos pelos organismos formadores, já os saberes experienciais são aqueles produzidos pelos professores a partir de seu próprio trabalho, na prática cotidiana da profissão. Assim, a produção desses saberes tem como referência as múltiplas interações construídas em situações concretas nas quais os saberes da formação inicial são enredados por outros, de outros professores e dos alunos em sua potencialidade e necessidades, o que cria o tecido da prática e da formação (em) caminhos de educação outra, uma história ainda em 
construção, que pode ser potencializada pelas pesquisas desenvolvidas pelos profissionais sobre seu próprio trabalho.

A educação inclusiva, cujo fundamento é a garantia do acesso e a permanência de todos os alunos nas escolas de ensino regular, tem por base de seus princípios as ações e os programas voltados a essa construção:

\begin{abstract}
A ideia de uma sociedade inclusiva se fundamenta numa Filosofia que reconhece e valoriza a diversidade como característica inerente à constituição de toda e qualquer sociedade. Partindo desse princípio e tendo como horizonte o cenário ético dos Direitos Humanos, sinaliza a necessidade de se garantir acesso e participação de todos, a todas as oportunidades, independente das peculiaridades de cada indivíduo e/ou grupo social (BRASIL, 2004, p. 8).
\end{abstract}

Na complexidade e na multidimensionalidade que cercam a ideia de uma educação escolar realmente inclusiva, as reflexões têm como referência os movimentos e as políticas nacionais e internacionais e as legislações e os documentos oficiais que materializam essas políticas. Um exemplo deles é a Declaração Mundial sobre Educação para Todos, fruto da Conferência Mundial sobre Educação para Todos, que se realizou em Jomtien, em 1990 (UNESCO, 1998a). O Artigo 3 afirma o direito universal à educação e a necessária melhoria de sua qualidade e, como forma de garantir esse direito a todos, afirma, também, a urgência de medidas e ações voltadas à construção dessa educação. É importante observar que o foco das atenções e ações, de acordo com o Artigo 4ำ da mesma Declaração, não deve restringir-se à matrícula, mas se destinar à garantia de acesso e de permanência na escola, e ao desenvolvimento e aprendizagem das crianças e dos jovens.

Na Declaração de Salamanca (UNESCO, 1998b), assinada em 1994, encontramos os direcionamentos necessários à efetiva inclusão escolar de todas as crianças, independente das diferenças que possam existir entre elas - o que gerou um grande desafio aos sistemas escolares. Essa Declaração reafirma a desejável reorganização pedagógica escolar e curricular, através da adoção de sistemas que considerem as diferentes precisões das crianças e dos jovens. O documento alerta ainda que as escolas devem oferecer oportunidades apropriadas ao aluno com habilidades e interesses diferentes:

O princípio que orienta esta Estrutura é o de que as escolas deveriam acomodar todas as crianças independentemente de suas condições físicas, intelectuais, sociais, emocionais, linguísticas ou outras. Aquelas deveriam incluir crianças deficientes e superdotadas, crianças de rua e que trabalham, crianças de origem remota ou de população nômade, crianças pertencentes a minorias linguísticas, étnicas ou culturais, e crianças de outros grupos desavantajados ou 
marginalizados. No contexto desta Estrutura, o termo "necessidades educacionais especiais" refere-se a todas aquelas crianças ou jovens cujas necessidades educacionais especiais se originam em função de deficiências ou dificuldades de aprendizagem. Escolas devem buscar formas de educar tais crianças bemsucedidamente, incluindo aquelas que possuam desvantagens severas. Existe um consenso emergente de que crianças e jovens com necessidades educacionais especiais devam ser incluídas em arranjos educacionais feitos para a maioria das crianças. Isto levou ao conceito de escola inclusiva. O mérito de tais escolas não reside somente no fato de que elas sejam capazes de prover uma educação de alta qualidade a todas as crianças: o estabelecimento de tais escolas é um passo crucial no sentido de modificar atitudes discriminatórias, de criar comunidades acolhedoras e de desenvolver uma sociedade inclusiva (UNESCO, 1998b, s/p.).

No Brasil, a construção de uma educação para todos, que, para assim se constituir, deve partir da garantia e da promoção da própria cidadania, está presente na Constituição Federal de 1988 (BRASIL, 2010a), na Lei n. 8.069 de 13 de julho de 1990 (BRASIL, 2001a), que dispõe sobre o Estatuto da Criança e do Adolescente, e na própria Lei de Diretrizes e Bases da Educação Nacional - a Lei n. 9394 de dezembro de 1996 (BRASIL, 2010b).

Os encaminhamentos necessários para que os sistemas e escolas brasileiros tornem-se inclusivos estão, também, dispostos na Resolução n. 2, de 11 de setembro de 2001, que institui as Diretrizes Nacionais de Educação Especial na Educação Básica (BRASIL, 2001b), no documento Política Nacional da Educação Especial na Perspectiva da Educação Inclusiva (BRASIL, 2008) e na Resolução n. 4, de 2 de outubro de 2009 (BRASIL, 2010c), que institui as Diretrizes Operacionais para o Atendimento Educacional Especializado na Educação Básica - Modalidade Educação Especial.

A partir do exposto nos textos legais, destaca-se a convergência entre as políticas educacionais, um projeto político-pedagógico escolar que contemple a diversidade e que a leve em consideração na organização do currículo escolar, e, como terceiro vértice, as práticas pedagógicas desenvolvidas pelos professores em sala de aula, em interação com os alunos. Mas a pergunta que deve ser feita, quando se trata da educação inclusiva, é: como e/ou em que medida as determinações legais se convertem em ações concretas que atinjam as escolas e cheguem aos sujeitos interessados? Nossas observações revelam que, embora a discussão faça referência a alunos que, por diferentes motivos, estão afastados (de certa forma, foram afastados) do processo de escolarização formal e devem ser incluídos na escola e nas salas de aula, ela comumente assume a indicação de adaptações individuais para cada aluno, sem que sejam consideradas a compreensão e a superação das barreiras 
que historicamente os têm afastado da escola e que envolvem os aspectos políticos e pedagógicos desse processo.

Com Carvalho (2010), porém, reafirmamos a concepção da inclusão escolar como processo social que não pode ser pensado separadamente de outros processos, decorrendo dessa premissa que a escolarização, aprendizagem e desenvolvimento de todos os alunos deveriam ser os objetivos dos profissionais, da escola e da sociedade em geral, na busca da construção de uma educação realmente inclusiva.

\section{A pesquisa desenvolvida: contribuições na formação profissional do professor}

A pesquisa a que fazemos referência neste texto foi desenvolvida em escola pública do sistema municipal de uma cidade do interior do Estado de São Paulo, tendo como objetivo investigar os processos formativos na relação com as práticas pedagógicas dos professores. Foram sujeitos dessa pesquisa onze professores dos anos finais do Ensino Fundamental (sexto ao nono ano), estando entre eles a professora que atuava diretamente no atendimento a alunos com necessidades educacionais especiais e na orientação dos demais professores e familiares. A professora e sua função são nomeadas nessa rede de ensino por professor de Educação Especial e é dessa forma que faremos referência a essa profissional.

No município, os professores de Educação Especial assumem diferentes modalidades de atendimento aos alunos que apresentam necessidades educacionais especiais, como: atuação na classe comum, em salas de recursos multifuncionais (atualmente o AEE - Atendimento Educacional Especializado), em classe hospitalar e no atendimento domiciliar. Os profissionais trabalham diretamente com os alunos, orientam familiares e demais professores, bem como participam das atividades escolares coletivas, como as reuniões pedagógicas. A professora da nossa pesquisa atendia os alunos com necessidades educacionais especiais em sala de aula, junto com o professor responsável pela classe, e em atendimentos individualizados realizados no contraturno; não havia, no período, sala de recursos multifuncionais na escola.

A instituição atendia cerca de quinhentos alunos, oferecendo Ensino Fundamental em três turnos de funcionamento: matutino, intermediário e vespertino. O bairro onde está 
localizada é habitado por famílias de trabalhadores do comércio e das indústrias da região de Campinas, sendo que muitos deles enfrentavam o desemprego. Constatamos que, ao final do Ensino Fundamental, a expectativa dos alunos e familiares era de que os primeiros concluíssem o Ensino Médio, visando a melhores condições de vida e trabalho. Entretanto, muitos saíam do Ensino Fundamental já buscando um trabalho que lhes possibilitasse ajudar a família, o que os levava à transferência para o turno noturno e, em alguns casos, ao abandono dos estudos. O apelo econômico e o consumo eram, e continuam sendo, a motivação de muitos alunos e familiares, e a escola e seus profissionais atuavam e atuam no sentido de indicar outras possibilidades.

A escola é viva e seu cotidiano é marcado pela complexidade e pelas contradições produzidas entre o micro e o macro espaços, entre os sujeitos e as políticas públicas educacionais, entre as famílias, a comunidade e o próprio sistema de ensino municipal. No período em que a pesquisa foi desenvolvida, a escola refletia em seu interior propostas e orientações da rede, que apontavam para mudanças curriculares, organizacionais, administrativas e profissionais que seriam decisivas para a escola e seus professores nos anos por vir. Por outro lado, e relacionadas diretamente à aprendizagem dos alunos, refletia também as inquietações dos professores acerca do baixo desempenho escolar e da pouca interação com eles, o que, segundo os docentes, estendia-se à dificuldade de ensinar. A essa escassa interação acresciam-se os problemas de indisciplina, conforme relatado, como a não aceitação das regras escolares, havendo queixas generalizadas entre os docentes. Porém, ao ouvir os alunos, percebiam-se também as dificuldades de interação com os professores que, segundo eles, desconsideravam sua realidade e suas necessidades.

Outra dificuldade dos professores (de classe comum e também da professora de Educação Especial) era com os alunos com necessidades educacionais especiais. Eles se questionavam sobre possíveis práticas que promovessem o envolvimento e participação desses alunos nas atividades de sala de aula e maior desenvolvimento e aprendizagem. Vale ressaltar que os alunos estavam inseridos em classes do ensino regular e, portanto, os professores se referiam a práticas comuns a todos os alunos.

As dificuldades presentes no cotidiano escolar ocasionaram, em um primeiro momento, certa decepção e desânimo, que transpareciam na fala dos professores. Porém, para alguns, também propiciou a busca por respostas, e, nesse sentido, o contato com um 
grupo de pesquisadores de uma universidade pública da região levou ao desenvolvimento, na escola, de ações investigativas e de estudo desenvolvidas em colaboração entre professores da escola e professores-pesquisadores da universidade, tendo como objetivo a melhoria da instituição e do trabalho docente. A ação central da parceria foi o desenvolvimento do Projeto Escola Singular, Ações Plurais que envolvia estudos e pesquisas e que foi coordenado por dois pesquisadores da universidade. Desse grande Projeto (SADALLA; PRADO, 2007) participou quase a totalidade dos professores da escola, os quais, como pesquisadores bolsistas ${ }^{2}$, refletiram e pesquisaram sobre seu trabalho. A perspectiva adotada por este Projeto tomava como referência a perspectiva do professor que pesquisa e reflete sobre sua prática em interlocução com seus pares, nos embates do cotidiano escolar e profissional, na vivência das dúvidas e dificuldades postas à sua prática.

O projeto Escola Singular, Ações Plurais propunha as seguintes ações: pesquisas individuais dos professores a partir de demandas cotidianas do exercício profissional, da escola e da sala de aula; organização dos professores em grupos (os chamados GTs - Grupos de Trabalho, em que se reuniam todos os professores, e os GTzinhos, que eram subgrupos), dentro dos quais se discutiam questões curriculares e do ensino e aprendizagem, a partir das temáticas das pesquisas (comuns, no caso dos GTzinhos); elaboração pelos professores de relatórios de pesquisa semestrais encaminhados aos coordenadores do Projeto, que, por sua vez, os dirigiam à agência de fomento como parte dos relatórios gerais do projeto. Observase, pelo exposto, que as ações pautavam-se no trabalho coletivo, na organização de grupos de estudo e na potência da escrita dos relatórios de pesquisa, uma vez que foram apropriados e elaborados pelos participantes como um espaço-tempo de reflexões.

Paralelamente ao projeto Escola Singular; Ações Plurais, no mesmo período em que ele foi realizado (entre 2003 e 2008), foram desenvolvidas outras pesquisas que, embora com foco diferente (formação continuada, trabalho colaborativo, coordenação pedagógica, escrita docente, entre outras temáticas), tinham como eixo comum o trabalho docente, as reflexões sobre a prática e a colaboração entre sujeitos e instituições.

Uma dessas pesquisas, realizada por nós e cujos elementos principais apresentamos, tinha como objetivo investigar processos de formação desenvolvidos na escola; os dados foram levantados em entrevistas semiestruturadas realizadas com os

${ }^{2}$ Os participantes do projeto receberam bolsa de pesquisa da FAPESP - Fundação de Amparo à Pesquisa do Estado de São Paulo, o que em muito contribuiu no desenvolvimento de suas pesquisas. 
professores. Em função de seu poder de mobilização nos professores, nesta pesquisa foram também tomados como elemento de investigação os Relatórios de Pesquisa dos professores participantes do projeto Escola Singular, Ações Plurais, que apresentavam os sentidos produzidos por eles para sua prática profissional, indicando como a experiência de participar de uma pesquisa foi formativa e potencializadora das reflexões sobre a escola e sala de aula. O emprego dos Relatórios de Pesquisa deveu-se à compreensão da escrita como instrumento de reflexão e de formação para o professor (PRADO; FERNANDES, 2008, 2009).

No encaminhamento do referido trabalho, buscou-se pelo estabelecimento de parcerias entre os professores da escola e os pesquisadores da universidade, assumindo como base metodológica a pesquisa colaborativa (FIORENTINI, 2004). Sobre tal perspectiva, na última década têm sido desenvolvidas práticas colaborativas de pesquisa que exigem que professores e pesquisadores se reconheçam mutuamente como produtores de conhecimento, relação que pode ser mobilizadora de construções partilhadas e da ressignificação daquilo que, inicialmente, conheciam. A interlocução, constitutiva dos profissionais e de seus saberes, é mobilizada em tal perspectiva de pesquisa e sentidos são produzidos na relação, na escola, entre diferentes sujeitos - professores e pesquisadores que atuam nesse contexto, essencialmente coletivo.

Como já afirmamos, as interlocuções estabelecidas e as reflexões sobre a prática profissional, objeto das pesquisas desenvolvidas na escola, visavam a busca de soluções para as dúvidas e inquietações dos professores sobre situações de ensino, entre essas, o atendimento de alunos que apresentavam dificuldades para aprender, também em função de deficiências.

\subsection{A escola e a prática do professor: contextos da pesquisa e da formação}

Apresentamos, na sequência, excertos dos Relatórios de Pesquisa [RP] e da transcrição das Entrevistas [E] realizadas com os professores dos anos finais do Ensino Fundamental, dentre eles a professora que trabalhava diretamente com os alunos com necessidades educacionais especiais matriculados nessa escola.

Sob a perspectiva da relação entre pesquisa e formação, o que mobilizava os professores eram dificuldades que se apresentavam ao exercício cotidiano da profissão e aos 
conhecimentos da formação inicial. Nesse sentido, da busca de respostas às suas inquietações, a proposta de refletir sobre a prática, individual e coletivamente, apresentouse a eles como possibilidade de mudanças, e o projeto Escola Singular, Ações Plurais foi assumido como instrumento dessa reflexão. Os dizeres dos professores nos Relatórios de Pesquisa e Entrevistas apresentam potentes reflexões sobre o trabalho docente propiciadas pela sua participação na pesquisa desenvolvida na escola:

\begin{abstract}
Esse projeto surgiu de uma necessidade da própria escola, em um movimento de busca de soluções para os dilemas por nós enfrentados em nosso cotidiano. Por este motivo, a equipe de gestão (diretora, vice-diretora e orientadora pedagógica) também participa dele, o que facilita bastante o andamento do trabalho. Estando todos envolvidos (mesmo sabendo que há diferentes níveis de envolvimento e de crença), as necessidades são sentidas por todos e há maior facilidade em compreender as prioridades e as necessidades do grupo [RPM ${ }^{3}{ }^{3}$.
\end{abstract}

Este projeto teve início com a procura de solução para o problema de indisciplina que afligia todo o corpo docente e julguei ser importante a minha participação visto que tinha grandes problemas de indisciplina em sala de aula. Além disso, vi o projeto como uma oportunidade de estudar esta temática e tentar compreender a questão, trocar experiências com os colegas e assim chegar a uma solução [RPR1].

Novos parceiros integraram-se ao grupo de estudo, um projeto mais amplo nos trouxe a oportunidade de pensamento e ação sobre a realidade, as expectativas anteriores foram atenuadas. A constituição do novo grupo foi um processo de aproximação, sedução e confiança, a conquista do espaço de um trabalho de equipe, os coordenadores do grupo com suas orientações aos nossos dilemas pedagógicos, nos esclarecimentos de temas estudados como a indisciplina, a avaliação, os processos de ensino-aprendizagem, a motivação, refletidos e discutidos com diferentes visões, foram parceiros que incentivaram a prática profissional pensada numa perspectiva de mudança e diálogo [RPMA1].

Nos excertos que seguem, observa-se que dificuldades foram disparadoras das suas buscas e investigações e serviram de estímulo à pesquisa que desenvolveram coletivamente. No cotidiano da escola e no exercício docente, o aluno, com suas potencialidades e necessidades, mobilizava o professor a buscar outros caminhos para ensinar. A inclusão escolar de alunos que, historicamente, permaneciam fora da educação formal promoveu, e tem promovido, a desestabilização de certezas:

Tenho como experiência própria o caso de um aluno que no quinto ano não realizava as atividades, tinha sempre que chamar sua atenção para ele começar a fazê-las e terminá-las, pois sempre parava. Muitas vezes, enquanto grande parte da sala havia terminado, ele estava ali parado, algumas vezes conversando ou brincando com o colega. "Professor, você pega no meu pé!" - passou a responder.

\footnotetext{
${ }^{3}$ Às siglas RP (Relatório de Pesquisa) e E (Entrevista) foram acrescentados a inicial do nome de cada um dos professores ( $R, M, A, S$ e $M A)$ e o número do excerto, segundo sua apresentação na sequência deste texto.
}

Educação: Teoria e Prática/ Rio Claro/ Vol. 24, n.46/ p. 04-22/ Mai-Ago. 2014. 
Tinha somente desempenho insatisfatório e não conseguiria acompanhar o sexto ano. [...] Resolvi, então, convocá-lo; queria acompanhá-lo individualmente para ver se identificava algum problema. Como era véspera de prova, resolvi simplesmente estudar junto com ele a matéria e mostrar que eu queria apenas ajudá-lo. Fazia o que eu propunha e até perguntava o que não entendia, coisa que nunca fez em sala de aula. Provavelmente tenham outros fatores que influenciaram sua mudança, mas é admirável como um simples investimento na relação com o aluno pode levar a um resultado tão positivo na aprendizagem [RPR2].

Tendo como foco uma dúvida ou dificuldade, a pesquisa sobre a própria prática (que, para além da identificação dessa dificuldade, implica em seu acompanhamento a partir de observações e reflexões sistemáticas) pode, efetivamente, promover mudanças no trabalho docente, nas construções em sala de aula e, por consequência, contribuir para o desenvolvimento e a aprendizagem dos alunos, conforme indica o excerto abaixo:

Tendo como objetivo do projeto estudos e reflexões que levassem às mudanças em sala de aula para melhorar o processo de ensino-aprendizagem, mudanças baseadas em fundamentos teóricos e/ou experiências vividas ou compartilhadas, significando muitas vezes uma quebra de crenças e mitos que se arrastam há séculos na educação, tive clareza da forma como penso e vejo os alunos. Primeiro uma crença: acreditava que após trabalhar certo conteúdo com os alunos, aplicaria uma prova individual para verificar se o aluno aprendeu ou não, cujo parâmetro utilizado seria o resultado da prova, que supunha estar diretamente atrelada ao aprendizado. Tão simples: faria, desta forma, uma avaliação do conhecimento dos alunos. Porém, baseado na leitura e discussão no GTzinho, pude concluir realmente que era uma crença [RPR3].

Para esse professor, as dúvidas e necessidades põem em xeque as crenças, fazendo com que construa um fazer docente mais acertado em relação à realidade, baseado na reflexão sobre a própria atuação, o que sua participação na pesquisa propiciou.

Também para a Professora S., o cotidiano escolar e a sala de aula são potencializadores de reflexões sobre o fazer e saber do docente. Nesses contextos, naquilo que respondem ao professor, os alunos podem Ihe indicar a necessidade de mudanças:

Mesmo considerando que toda a classe foi muito bem, a maneira como foi dada aquela aula pode não ter sido adequada para aquele aluno. Pude verificar isso graças a essas reflexões. [...] Todos os alunos haviam realizado o trabalho e entenderam a proposta; parecia tudo tranquilo para aquela turma. Porém, um dos alunos fez o trabalho completamente fora da proposta. Conversando com ele, percebi que não havia entendido a proposta. Ele ficou nervoso e até chorou porque fez diferente dos outros. Expliquei para ele de forma diferente e ele entendeu [RPS1].

Para a professora dedicada aos alunos com necessidades educacionais especiais,

Professora A., as dúvidas e os questionamentos geram incertezas que podem ser disparadoras da reconstrução do que sabe a professora sobre sua própria atuação: 
É, não sei, às vezes, sabe, eu questiono: será que eu estou dando conta? Será que está certo, será que é por aí? Porque este ano a gente já pensou muito sobre o trabalho. Atende na sala? Atende fora da sala? Aí você começa a atender na sala e você fala: "Não, não é assim. Precisa fazer de outro jeito" Ai, tá: "Não vamos mais ficar dentro da sala". E agora? Isso está certo? E tem uma hora que você nem sabe se já fez alguma coisa porque já mudou tanto. Foi pra lá, foi pra cá [EA1].

Para essa profissional, que ensinava a alunos cujo desenvolvimento e desempenho escolar exigiam atendimento diferenciado, as dúvidas que mobilizavam suas buscas a levavam a questionar o seu trabalho:

Por exemplo, a aluna até agora não aprendeu Braile, então você fica pensando... Parece não ter tido mudança nenhuma mas, se você observa um pouquinho, avalia a situação, ela não tem mais medo de ficar sozinha. $O$ bebedouro! O refeitório! Tem a maior agilidade na hora da refeição. Fica sozinha numa boa. Hoje, você viu, entrou na sala correndo. Então, alguma coisa está dando certo. Mas eu fico pensando: será que eu tive alguma participação nisso? Onde foi? Por que eu não consigo achar. Tanta coisa já mudei. Onde foi minha participação? [EA2]

Os questionamentos que seguem, do Relatório de Pesquisa da mesma professora [RPA1], tocam na implicação do fazer e saber de um professor com o de outros professores, referindo-se, em última instância, à necessária parceria entre eles:

Que atuação com o aluno deverá acontecer para que ele seja realmente beneficiado? Quando atuar? Como atuar, dentro da sala de aula ou individualmente? Como não prejudicar a rotina? Fora da sala, estaria excluindo? Devo esperar o professor pedir ajuda? E quando não pede? O que num primeiro momento de conversa pude perceber é que o que tem feito o professor da classe, na maior parte dos casos, é pedir orientação do professor de Educação Especial quando o aluno não produz como espera. Será que todos aqueles alunos que não produzem como espera o professor necessitam realmente de uma atenção especial ou é a maneira como acontece o processo ensino-aprendizagem para aquele aluno que é diferente do que se espera? [RPA1]

O trecho "o que num primeiro momento de conversa pude perceber" [em RPA1] se refere às ações de pesquisa dessa professora (participante do projeto Escola Singular, Ações Plurais), que entrevistou outros professores sobre a inclusão escolar de alunos com necessidades educacionais especiais. No mesmo excerto, o questionamento da professora "ou é a maneira como acontece o processo ensino-aprendizagem para aquele aluno que é diferente do que se espera?"[RPA1] - diz de dúvidas que resultam da ausência de parceria e de trabalho conjunto. Em outro trecho [RPA2], a professora reafirma a importância da reflexão crítica e partilhada, coletiva, na superação de problemas e no desenvolvimento da prática docente: 
Para pensar em uma escola aberta à diversidade, acredito que haja necessidade de pensar em que medida temos favorecido a aprendizagem de todos os alunos, considerando a pluralidade dentro da sala de aula. Como também é necessário que o professor entenda que seus alunos desenvolvem meios diferentes de aprendizagem e assim utilizam caminhos que o professor pode desconhecer. Percebo que para alguns professores, o aluno que apresenta uma necessidade educacional especial, com deficiência ou não, é responsabilidade única do professor de Educação Especial já que, segundo eles, não foram formados para isso. Porém, tenho percebido neste ano que esta resistência dos professores tem tomado novos rumos, tendo em vista que um grupo de professores tem se dedicado a alunos com necessidades especiais em seus projetos [RPA2].

Sobre a atuação da professora de Educação Especial no ensino regular, esta profissional não deve, e não pode, ser responsabilizada sozinha pela inclusão dos alunos com necessidades educacionais especiais. Como afirma Prieto (2007), os sistemas de ensino e as escolas devem construir proposta pedagógica voltada à inclusão desses alunos a ser assumida por toda a escola, através de ações coletivas e colaborativas, no que se inclui a interação entre este professor e o professor da classe comum no desenvolvimento de práticas inclusivas e na própria avaliação e encaminhamento desse aluno aos apoios oferecidos, na escola e na rede de serviços da comunidade.

M. A., outra professora da escola, afirma o contexto escolar como espaço-tempo de interlocuções importantes para o reconhecimento mútuo dos sujeitos que lá convivem, possibilitando substituir o individualismo por ações coletivas.

Encontro-me aqui, também personagem em um caminhar, adequando-se a estas tantas alterações. Nós que somos os sujeitos, os alunos, os pais, os funcionários, os professores, a equipe de gestão, ex-alunos, ex-funcionários, a comunidade escolar, fazendo o espaço ter vida, nas relações de encontros, desencontros, idas e vindas alteradas anualmente, modificações necessárias que deixam suas marcas. São as marcas das vivências e vínculos pessoais que nos enriquecem em nossa formação e constituição do que somos, a imagem, a autoestima, nos valores éticos e morais, enfim em nosso corpo e na alma. Isto se estabelece com a identificação com o outro, a afetividade, na amizade, me reconhecendo pertencente a um espaço no e para o grupo [RPMA2].

As reflexões e ações coletivas se constroem na complexidade do cotidiano escolar e são dependentes, ou participam, das relações e interlocuções estabelecidas entre alunos e professores. Para a Professora M., a relação individual-social na escola e na sala de aula é considerada como elemento da reconstrução do fazer docente:

Neste primeiro semestre alguns fatores acabaram dificultando a concretização de uma prática interdisciplinar mais efetiva. O primeiro deles diz respeito à troca dos professores substitutos, o que acabou acarretando grandes mudanças na constituição de nosso grupo. Precisamos, então, reiniciar todo esse trabalho de criação de vínculos com os novos professores que passaram a integrar o grupo.

Educação: Teoria e Prática/ Rio Claro/ Vol. 24, n.46/ p. 04-22/ Mai-Ago. 2014. 


\begin{abstract}
Além do estabelecimento de vínculos entre nós docentes, dentro do grupo, há também o desafio de estabelecer vínculos entre os novos professores e os alunos, que muitas vezes os "testam" muito no primeiro momento, o que dificulta o trabalho em sala de aula. Em vários momentos de nossas reuniões, aspectos referentes à relação professor-aluno tomaram conta das mesmas que acabaram se tornando espaços de queixas e desabafos em relação aos problemas e dificuldades vivenciados em sala de aula [RPM2].
\end{abstract}

No excerto apresentado anteriormente [RPM2] a expressão "em vários momentos de nossas reuniões" se refere ao GT - Grupo de Trabalho formado por todos os professores participantes do projeto Escola Singular, Ações Plurais, e também aos encontros do GTzinho. A afirmação da Professora M. é indicativa de sua apropriação desses espaços coletivos como promotores de interlocuções, reflexões e mudanças. E deve-se ressaltar que o encaminhamento metodológico dado ao Projeto possibilitou essa apropriação, o que se estendia à pesquisa de cada professor. Nessa perspectiva de fazer pesquisa, a demanda profissional é levada em conta e não se desvincula o estudo da prática e, da mesma forma, as ações de pesquisa são também coletivas. Uma investigação com esse encaminhamento pode ser efetivamente formativa para os profissionais participantes.

\title{
3 Considerações finais
}

No contexto escolar e no novo cenário que se anuncia com cada novo/outro aluno que adentra o contexto escolar, entre a individualidade e a dinâmica escolar, os professores constroem e desconstroem continuamente seus fazeres e saberes. Dentre complexidades e mudanças, os saberes da formação inicial se entrelaçam aos saberes do exercício profissional na construção amalgamada dos saberes. É o sentido de formação profissional continuada centrada na escola e no exercício profissional e as pesquisas desenvolvidas pelos professores mostram-se como encaminhamentos adequados a essa construção.

O professor, conhecido e reconhecido como autor, no exercício da docência, observa, sistematiza e reflete sobre seu fazer e saberes em interlocução com outros sujeitos, alunos e demais professores. Especificamente, no caso do olhar do professor sobre o aluno, da construção de práticas pedagógicas voltadas à sua potencialidade e necessidade e, principalmente, dirigidas para a construção de escola e educação inclusiva, a pesquisa desenvolvida pelos professores na escola indicou-lhes a necessidade de rever - no sentido de 
ver novamente - o cotidiano escolar e o trabalho docente.

Entre os vários aspectos, a fala e escrita dos professores apresentadas neste artigo disseram da importância do trabalho coletivo e cooperativo, das ações integradas entre a professora de Educação Especial e os professores de classe comum e, também, da necessidade de se repensar a própria concepção de educação e de educação inclusiva dos profissionais envolvidos.

A educação inclusiva tem sido construída como um grande desafio à educação e à sociedade atual. A diversidade cultural e social, e distintos modos de aprender, constituem cada grupo de escolares; não é condição atípica ou que exija profundas mudanças, mas, assumimos com os professores, há muito a ser pensado e feito. As reflexões dos professores apontaram para a necessidade de que se promovessem outras possibilidades de ensinar e de aprender para alunos que, situados até o presente momento à margem dos processos de escolarização formal, estão hoje em nossas escolas e salas de aula.

\section{Referências}

BRASIL. Constituição da República Federativa do Brasil. Texto constitucional promulgado em 5 de outubro de 1988. Brasília: Senado Federal/Secretaria Especial de Editoração e Publicações, 2010a. 47 p.

BRASIL. PRESIDENCIA DA REPÚBLICA. CASA CIVIL. Lei n. 9.394, de 20 de dezembro de 1996. Estabelece as diretrizes e bases da educação nacional. Brasília: Câmara dos Deputados, 2010b. 64 p.

BRASIL. Ministério da Educação. Conselho Nacional de Educação. Câmara de Educação Básica. Resolução no 4, de 2 de outubro de 2009. Institui as Diretrizes Operacionais para o Atendimento Educacional Especializado na Educação Básica - Modalidade Educação Especial. Marcos político-legais da Educação Especial na perspectiva da educação inclusiva. Brasília: MEC/SEESP, 2010c. p. 69-72. Disponivel em: <http://pfdc.pgr.mpf.gov.br/atuacao-econteudos-de-apoio/publicacoes/educacao/marcos-politico-legais.pdf>. Acesso em: 20 de out. 2013.

BRASIL. Ministério da Educação. Secretaria de Educação Especial. Política Nacional de Educação Especial na Perspectiva da Educação Inclusiva. Brasília: MEC/SEESP, 2008. Disponível em: <http://portal.mec.gov.br/seesp/arquivos/pdf/politica.pdf>. Acesso em: 20 de out. 2013.

BRASIL. Ministério da Educação. Secretaria de Educação Especial. Educação Inclusiva. Fundamentação Filosófica. Brasília: MEC/SEESP, 2004. 30 p. 
BRASIL. PRESIDENCIA DA REPÚBLICA. CASA CIVIL. Lei n. 8.069, de 13 de julho de 1990.

Dispõe sobre o Estatuto da Criança e do Adolescente e dá outras providências. Brasília: Senado Federal, 2001a. 208 p.

BRASIL. Ministério da Educação. Secretaria de Educação Especial. Resolução n. 2, de 11 de setembro de 2001. Institui Diretrizes Nacionais para a Educação Especial na Educação Básica. Diário Oficial da União, Brasília, DF, 14 de set. 2001b. Seção 1E, p. 39-40. Disponível em: www.portal.mec.gov.br/cne/arquivos/pdf/CEB0201.pdf. Acesso em: 25 de out. 2013.

CARVALHO, R. E. Inclusão Escolar: Desafios. In: SEMINÁRIO SOCIEDADE INCLUSIVA, 6., 2010, Belo Horizonte. Anais... Belo Horizonte: PUCMINAS, 2010. p. 1-15. CDRom.

ELLIOTT, J. Recolocando a pesquisa-ação em seu lugar original e próprio. In: GERALDI, C.; FIORENTINI, D.; PEREIRA, E. (Orgs.) Cartografias do trabalho docente: professor(a)pesquisador(a). Campinas: Mercado das Letras/ALB, 1998. p. 137-152.

FIORENTINI, D. Pesquisar Práticas Colaborativas ou Pesquisar Colaborativamente? In: BORBA, M. C. ; ARAÚJO, J. L. (Orgs.). Pesquisa qualitativa em educação matemática. Belo Horizonte: Autêntica, 2004. p. 47-76.

GERALDI, C. M. G.; FIORENTINI, D.; PEREIRA, E. M. A.(Org.). Cartografias do trabalho docente. Campinas: Mercado de Letras/ ALB, 1998. 336p.

JAPIASSU, H. A Pedagogia da incerteza e outros estudos. Rio de Janeiro: Imago, 1983. 171 p.

PRADO, G. V. T.; SOLIGO, R. (Orgs.). Porque escrever é fazer história: revelações, subversões e superações. Campinas: Abaporu/Gepec/FE-UNICAMP, 2005. 368 p.

PRADO, G. V. T.; CUNHA, R. B. (Orgs). Percursos de Autoria: exercícios de pesquisa. São Paulo: Alínea. 2007. 230 p.

PRADO, G. V. T.; FERNANDES, C. H. Saberes docentes tecidos na escrita: pontos do fazer constituídos na autoria e na interlocução. In: LACERDA, M. P. (Org.) A escrita inscrita na formação docente. Rio de Janeiro: Rovelle, 2009. p. 37-64.

PRADO, G. V. T.; FERNANDES, C. H. A narrativa na formação de professoras e de pesquisadores da/na escola: diários de viagem. Educação Unisinos, São Leopoldo, v. 1, n. 12, p. 16-27. 2008.

PRIETO, R. G. Professores especializados de um centro de apoio: estudo sobre saberes necessários para sua prática. In: JESUS, D. M. et al. (Org.?) Inclusão, práticas pedagógicas e trajetórias de pesquisa. Porto Alegre: Mediação, 2007. p. 281-294.

SADALLA, A. M. F.; PRADO, G.V.T. Em busca da construção de uma escola reflexiva: relatando uma parceria entre universidade e escola. Saber (e) Educar, Porto, v. 12,n.1, p. 97-107. 2007. 
STENHOUSE, L. An introduction to curriculum research and development. Londres: Heinemann, 1975.

TARDIF, M. Saberes docentes e formação profissional. 8. ed. Petrópolis: Vozes, 2007. 328 p.

UNESCO. Declaração Mundial Sobre Educação Para Todos. Satisfação das Necessidades Básicas de Aprendizagem. In: CONFERÊNCIA MUNDIAL SOBRE EDUCAÇÃO PARA TODOS, 1., 1990, Jomtien. Anais... Brasília: UNESCO, 1998a. p. 1-8. Disponível em: http://unesdoc.unesco.org/images/0008/000862/086291por.pdf . Acesso: 25 de out. 2013.

UNESCO. Declaração de Salamanca e Enquadramento da Ação na Área das Necessidades Especiais. In: CONFERÊNCIA MUNDIAL SOBRE EDUCAÇÃO PARA AS NECESSIDADES ESPECIAIS: ACESSO E QUALIDADE, 1., 1994, Salamanca. Anais... Brasília: UNESCO, 1998b. Disponível em: <http://unesdoc.unesco.org/images/0013/001393/139394por.pdf>. Acesso: 25 de out. 2013.

VARANI, A.; FERREIRA, C. R.; PRADO, G. V. T. (Orgs). Narrativas Docentes: trajetórias de trabalhos pedagógicos. São Paulo: Mercado de Letras. 2007. 352 p.

VICENTINI, A.; FARIAS, M. N. O.; SADALLA, A. M. F. A.; PRADO, G. V .T. (Orgs). ProfessorFormador: histórias contadas \& cotidianos vividos. Campinas: Mercado de Letras, 2008. 168 p.

ZEICHNER, K. Tendências da pesquisa sobre formação de professores nos Estados Unidos. Revista Brasileira de Educação, inserir cidade de publicação, inserir v., n. 9, p.76-87, set./out./nov./dez. 1998a.

ZEICHNER, K. Para além da divisão entre professor-pesquisador e pesquisador-acadêmico. In: GERALDI, C. M. G.; FIORENTINI, D.; PEREIRA, E. M. A.(Org.). Cartografias do trabalho docente. Campinas: Mercado de Letras/ALB, 1998b. p. 207-236.

Enviado em Dezembro/2012

Aprovado em Novembro/2013 